\title{
Quando as Práticas da Formação Inicial se Aproximam na e pela Pesquisa do Contexto de Trabalho dos Futuros Professores
}

\section{When Initial Training Practices Become Closer Together In and Due to Research into the Work Environment of Future Teachers}

Rosenilde Nogueira Paniago'

Patrícia Gouvêa Nunes ${ }^{1}$

Fátima Suely Ribeiro Cunha²

Paulo Alberto da Silva Sales ${ }^{3}$

Calixto Junior de Souza'

\begin{abstract}
'Instituto Federal de Educação, Ciência e Tecnologia Goiano, Centro de Educação Rosa de Saberes, Rio Verde, GO, Brasil. Autora correspondente: rosenilde.paniago@ifgoiano.edu.br

'Instituto Federal de Educação, Ciência e Tecnologia Goiano, Goiânia' GO, Brasil.

İnstituto Federal de Educação, Ciência e Tecnologia Goiano, Hidrolândia, GO, Brasil.
\end{abstract}

Resumo: Neste artigo apresentam-se os resultados de uma pesquisa-ação realizada com estudantes das Licenciaturas em Química e Ciências Biológicas do Instituto Federal Goiano, cujo objetivo foi analisar como a pesquisa no processo formativo de professores possibilita a aproximação dos futuros professores da escola de educação básica. Como procedimentos, os Licenciandos foram orientados na elaboração e desenvolvimento de projetos de pesquisa, abordando temas relacionados à sua área de formação em escolas de educação básica. O presente texto foi construído a partir de nossas próprias narrativas como formadores e das narrativas dos Licenciandos registradas em diários de campo. Os resultados sinalizam a possibilidade de articulação do tripé: pesquisa, ensino e extensão, destacando a importância da aproximação dos futuros professores de Ciências de seu contexto de atuação profissional, assentada na e pela pesquisa.

Palavras-chave: Formação inicial de professores; Ensino de química; Ensino de biologia; Pesquisa-ação; Pesquisa participante.

Abstract: This article presents the results of action research carried out with undergraduate students in Chemistry and Biological Sciences at the Instituto Federal Goiano, in which the goal was to analyze how research in teacher education allows for the approximation of future teachers in basic education school. As part of the research procedures, the undergraduates were guided throughout the elaboration and development of research projects addressing themes related to their area of training in basic education schools. The present text has been built from our own narratives as trainers and from the undergraduates' narratives recorded in field journals. The findings indicate the possibility of a tripod articulation involving research, teaching and extension, and the importance of bringing future science teachers closer to their context of professional practice both based on research and through research.

Keywords: Initial teacher training; Chemistry teaching; Biology teaching; Action research; Participatory research.

Recebido em: 13/11/2019

Aprovado em: 22/04/2020 


\section{Introdução}

Cada vez mais, tem-se discutido sobre a importância e a necessidade da aproximação das práticas de ensino dos cursos de Licenciatura com o futuro campo de trabalho - o cotidiano da escola de educação básica. Vários teóricos têm se dedicado a esse debate, tais como Misukami (2013), Pimenta e Anastasiou (2014), Pimenta e Lima (2017), Tardif (2013), Zeichner (2008), dentre outros. O que se tem observado é que, geralmente, as práticas de ensino nas disciplinas que compõem a matriz curricular das Licenciaturas são fragmentadas entre si e dissociadas da realidade da escola de educação básica. A esse respeito, Zeichner (2008) aponta, como um desafio na formação de professores, a falta de relação entre o espaço de formação nas universidades e o campo da prática dos professores em formação.

Por certo, é necessário se pensar em ações que favoreçam a aproximação do estudante de Licenciatura com a vivência escolar e o trabalho colaborativo entre professores formadores da Instituição de Ensino Superior (IES) e os coformadores da Educação Básica.

Apreciando a urgência de se trabalhar a aproximação dos estudantes de Licenciatura da atividade docente, para contribuir com a identidade e aprendizagem profissional, observase uma vasta bibliografia, pela qual, são apresentadas muitas ideias e questionamentos, principalmente, sobre a formação inicial dos professores, e, mais especificamente, sobre a formação reflexiva e investigativa dos professores. Nesse cenário de produções, incluímonos, Paniago (2016), Paniago e Sarmento (2017), Paniago et al. (2018) e destacamos Alarcão (2011), Pimenta e Lima (2017), Vieira (2017) e Zeichner (1993, 2010).

Nessa perspectiva formativa, defendemos a importância e a necessidade de oportunizar, aos estudantes das Licenciaturas, uma aproximação investigativa das práticas de ensino no interior da escola, com vistas a contribuir para a formação de professores capazes de refletir sobre sua própria ação - professores pesquisadores de suas práticas com possibilidade de mobilizar ações inovadoras em sua prática de ensino, lutar por justiça social e investir em seu próprio desenvolvimento profissional.

Imbuídos desta concepção de formação, o fio condutor desta pesquisa', que se encontra em desenvolvimento desde 2017, assentou-se no desenvolvimento de projetos de investigação pedagógica no cotidiano da escola de educação básica, pelos Licenciandos das disciplinas de Prática de Ensino de Ciências, do curso de Licenciatura em Ciências Biológicas, e Prática de Ensino Aplicada à Química, do curso de Licenciatura Química, bem como bolsistas e voluntários que estavam sob a nossa orientação em projetos de ensino, pesquisa e extensão, desenvolvidos no Laboratório Interdisciplinar de Formação de Educadores (LIFE) ${ }^{2}$ sob a nossa coordenação. Tratamos da pesquisa pedagógica na acepção de Vieira (2017), um tipo de pesquisa que focaliza as questões do ensino e seus intervenientes e se coloca a

\footnotetext{
${ }^{1}$ A pesquisa registrada no comitê de ética da Plataforma Brasil envolve professores do Instituto Federal Goiano, participantes do grupo de pesquisa EducAção, aqui denominados como formadores, e professores da educação básica, denominados como coformadores.

${ }^{2} \mathrm{O}$ laboratório LIFE, lançado pela Coordenação de Aperfeiçoamento de Pessoal de Nível Superior (CAPES) por meio do edital 035/2012, representa um espaço de uso comum dos cursos de Licenciatura das Instituições de Ensino Superior, com vistas a promover a interação entre diferentes cursos de formação de professores, de modo a incentivar o desenvolvimento de metodologias e práticas pedagógicas diferenciadas. Ver mais em: http://www.capes.gov.br/educacao-basica/life. O espaço no IF Goiano, câmpus Rio Verde é destinado também a aulas práticas dos cursos graduação, especialmente os cursos de Licenciaturas, e ao curso de Pós-graduação em Formação de Professores e Práticas Educativas. Destina-se também a outros projetos, tais como o Núcleo de Estudos Afrobrasileiros e Indígenas (NEABI), espaço de formação para o Programa de Iniciação à Docência (PIBID), e Programa Residência Pedagógica (RP).
} 
serviço da qualidade da educação e do desenvolvimento profissional dos professores. Não obstante, esclarecemos que o LIFE faz parte do atual Centro de EducAção Rosa de Saberes, do Instituto Federal Goiano (IF Goiano), câmpus Rio Verde, espaço que acolhe professores, cujos projetos de ensino, pesquisa e extensão focalizam a formação de professores e o processo ensino e aprendizagem na educação básica.

Diante do exposto, este artigo visa apresentar resultados de uma pesquisa realizada com estudantes dos cursos de Licenciatura em Química e Licenciatura em Ciências Biológicas do Instituto Federal Goiano, câmpus Rio Verde, cujo objetivo foi analisar como a pesquisa no processo formativo de professores possibilita a aproximação dos Licenciandos da escola de educação básica. As questões que orientam a pesquisa são: Como materializar o processo de formação articulado ao chão da escola na e pela pesquisa? Como desenvolver nos Licenciandos habilidades para o desenvolvimento da pesquisa pedagógica na sua formação?

Como delineamento do texto, optamos por apresentar uma reflexão sobre a formação articulada ao chão da escola, seguida da trajetória da investigação, e, posteriormente, apresentaremos as práticas desenvolvidas, com vistas a materializar nossa intencionalidade de pesquisa.

\section{A Formação, Desenvolvimento Profissional e Aprendizagem Docente no Chão da Escola}

Nesta discussão, entendemos que o desenvolvimento profissional dos professores refere-se às aprendizagens adquiridas ao longo da vida, tal como já afirmamos o desenvolvimento profissional e a identidade desses profissionais se traduz pela "[...] aprendizagem contínua da docência, em uma perspectiva temporal, ao longo da vida e influenciada por diversos intervenientes: experiência pessoal, profissional, processos formativos e aspectos socioculturais, econômicos, políticos e ambientais". (PANIAGO, 2016, p. 140).

A identidade docente, a aprendizagem e o desenvolvimento profissional, portanto, são elementos, intrinsecamente, ligados, numa verdadeira simbiose, uma vez que o desenvolvimento profissional dos professores se traduz pelas aprendizagens do ser professor, que ocorrem ao longo da vida e que, por sua vez, constituem a identidade docente. Nesse sentido, já defendemos a importância de perspectivas formativas que suscitem o desenvolvimento profissional, por meio de reflexão e investigação colaborativa, acerca de problemáticas vinculadas à prática pedagógica, ao trabalho docente, à luta por melhores condições de trabalho, à valorização profissional e justiça social (PANIAGO, 2016, 2017). Conforme Flores (2010), o desenvolvimento profissional dos professores não se dá, apenas, como acúmulo de técnicas, métodos diferenciados, mas, sim, por meio de uma (re) construção coletiva constante de novas formas de ensino e aprendizagem. Segundo a autora, se são almejados professores comprometidos com o seu desenvolvimento profissional, em processos de pesquisa, reflexão e colaboração, "[...] é necessário promover tais atitudes nos professores em formação, o que implica uma (re)definição do papel das universidades e dos formadores de professores (e do que significa ser professor), num tempo em que os desafios que se colocam às universidades são cada vez mais exigentes". (FLORES, 2010, p. 144).

Evidentemente, sabemos que a aprendizagem e a identidade docente não são construídas apenas na formação inicial, uma vez que os Licenciandos em formação já 
vivenciaram as situações pedagógicas escolares como alunos, desde a educação básica, por meio da vivência e da observação das práticas de ensino de seus professores, vivência que se prolonga na formação inicial e depois por toda a vida profissional. Nessa direção, Tardif (2013, p. 17) afirma que "antes mesmo de ensinarem, os futuros professores vivem nas salas de aula e nas escolas - e, portanto, em seu futuro local de trabalho - durante, aproximadamente, 16 anos (ou seja, em torno de 15.000 horas)". No que diz respeito ao processo de identificação com a profissão, Pimenta e Lima (2017, p. 51) afirmam que "[...] a identidade do professor é construída ao longo de sua trajetória como profissional no Magistério. No entanto, é no processo de sua formação que são consolidadas as opções e as intenções da profissão que o curso se propõe legitimar".

Ao focalizarmos o desenvolvimento profissional dos professores como reflexivos e investigadores, entendemos que a escola, futuro campo de trabalho dos Licenciandos, é um espaço fundamental a ser considerado nessa perspectiva formativa, pois é matriz de aprendizagem múltipla e de conhecimento sobre a docência. Mizukami (2013, p. 23) reforça que "[...] por excelência, a escola constitui um local de aprendizagem e desenvolvimento profissional da docência". Na mesma direção, Alarcão (2011, p. 12) afirma que: "[...] é necessário investir bem, aprofundar a qualidade, fazer muita ligação com as escolas e criar comunidades de aprendizagens para os professores que estão nas escolas e, se possível, com os professores que estão a aprender a serem professores".

Também recorremos a Tardif (2013), ao anunciar que o saber docente é vinculado a situações de trabalho com alunos, colegas, pais, na tarefa complexa do processo de ensino, em sala de aula, no contexto histórico e social da instituição. Assim, é fundamental que a formação se efetive vinculada ao chão da escola de educação básica, futuro campo de trabalho dos professores em formação.

Zeichner (2010) nos ajuda ao pontuar a importância da aproximação da IES com as escolas de educação básica, reforçando que as experiências de campo necessitam ser planejadas e supervisionadas. O autor propõe a criação do terceiro espaço denominado como "espaço híbrido", no qual os professores de educação básica e da universidade se reúnam e se relacionem, de maneira menos hierárquica e mais igualitária, com vistas a promover formação qualificada dos futuros docentes. Essa perspectiva formativa vai ao encontro das práticas que defendemos e procuramos materializar como formadores de professores, na medida em que procuramos estabelecer uma relação dialógica com os professores da educação básica, de modo a equilibrar o conhecimento acadêmico e o da prática docente, e valorizá-los como coformadores.

Para além de defendermos uma formação na e pela pesquisa, vinculada ao trabalho profissional, advogamos pelo trabalho colaborativo entre os docentes (formadores, coformadores) e Licenciandos, considerando que o diálogo e ações coletivas ensejam o pensar e o fazer juntos. Tal como afirma Alarcão (2011, p. 34), "[...] o desenvolvimento do espírito crítico faz-se no diálogo, no confronto de ideias e de práticas, na capacidade de se ouvir o outro, mas também de se ouvir a si próprio e de se autocriticar. E tudo isto só é possível num ambiente humano de compreensiva aceitação [...]". Segundo a autora, os professores não podem ficar isolados em sala de aula, ao contrário, eles, em colaboração, "[...] têm de construir pensamento sobre a escola e o que nela se vive. É nesse contexto que ganham força os círculos de estudo e os grupos de discussão sobre temas candentes" (ALARCÃO, 2011, p. 63). 
Então, preocupamo-nos em desenvolver um processo formativo por meio do diálogo, criando espaço para a participação e incitando os professores da educação básica e Licenciandos a serem coparticipantes do processo, incluindo-os nas decisões, nas ações a serem desenvolvidas durante a pesquisa. Pimenta e Lima (2017, p. 36), ao destacarem a importância da aproximação com a realidade da escola de educação básica no ECS, de forma intencional, reflexiva, apontam que "[...] é preciso que os professores orientadores de estágio procedam, no coletivo, com seus pares e alunos, a essa apropriação da realidade, para analisá-la criticamente, à luz das teorias. Essa caminhada conceitual, certamente, será uma trilha para a proposição de novas experiências"

Ao falar em formação na e pela investigação, realçamos que estamos a tratar da pesquisa pedagógica, conforme defende Vieira (2017), um tipo de pesquisa que focaliza as questões do ensino e seus intervenientes. Para a autora,

Ao colocar a investigação ao serviço da qualidade da formação e do seu desenvolvimento profissional, os formadores podem contrariar uma tradição acadêmica, que tende a separar a investigação da formação e a relegar esta para um estatuto de segundo plano, tornando-se arquiteto de sua profissão. (VIEIRA, 2017, p. 150).

Reportamos, ainda, a Zeichner (1993), ao propor a discussão sobre o prático reflexivo, que é a prática orientada pela pesquisa. As práticas de Zeichner, como formador de professores, nos ajudam a (re)pensar a nossa, na medida em que ele se preocupou com a preparação de professores reflexivos, que sejam capazes, além de consumidores críticos de conhecimentos, de participarem de sua criação, tais como estudos etnográficos, estudos de caso, investigação-ação, esclarecendo que: "Por si, nenhuma destas estratégias significa nada de especial" (ZEICHNER, 1993, p. 27), e que o mais importante são os objetivos para os quais se direciona a sua utilização.

\section{Trajetória da Pesquisa}

Desenvolvemos esta pesquisa na abordagem qualitativa. Neste processo de pesquisa, mesmo que o pesquisador já tenha previsto, em seu projeto, o percurso a seguir, na investigação, ele é sujeito a mudanças, considerando que os fenômenos educativos são imprevisíveis, o que implica na ação e reflexão, bem como na avaliação e replanejamento dos caminhos. Como apontam Ghedin e Franco (2008), não é possível apreender a teia de relações e práticas escolares por meio de métodos objetivos, estanques e distanciados dessas relações históricas e sociais. Para os autores, os aspectos sócio-históricos das práticas educativas fazem com que elas sejam singulares, com variações no tempo e espaço, em suas formas organizativas e na natureza de suas intencionalidades.

No universo da pesquisa qualitativa, fundamentamos-nos nos pressupostos da pesquisa-ação, uma vez que, segundo Alarcão (2011, p. 50), a metodologia da pesquisaação tem como características importantes: "[...] a) a contribuição para a mudança; b) o caráter participativo, motivador e apoiante do grupo; c) o impulso democrático". Ainda como referência para a pesquisa-ação, tomamos as experiências de Zeichner (2008) com o trabalho da pesquisa-ação, como estratégia formativa, a fim de ajudar os futuros professores a desenvolverem teorias acerca da docência e da luta por justiça social. 
A pesquisa-ação fornece de fato um meio de professores em formação engajarem na análise de sua própria prática de ensino, de modo que tal análise possa tornar-se a base para o aprofundamento e a expansão de seu pensamento e, consequentemente, a incluir um olhar sobre as dimensões sociais e políticas de seu trabalho. Ela pode fazer isso de modo que minimize o grau de obediência estratégica, por parte dos estudantes em estágio, e que possa começar a construir um compromisso autêntico dos professores em formação acerca do trabalho em prol da mudança social em sua prática de sala de aula. (ZEICHNER, 2008, p. 85).

Partimos do pressuposto que, como professores formadores, era preciso desenvolver a pesquisa-ação em nossa prática e suscitar nos Licenciandos atitude de investigação, para que, futuramente, estes possam fazer uso dessa atividade em sua prática pedagógica. Afinal, como iríamos incitá-los à iniciação à pesquisa pedagógica, se dela não fizéssemos uso em nossa prática? A partir desse pressuposto, realçamos que há 20 anos defendemos e realizamos a pesquisa pedagógica. Prática que teve início no magistério da educação básica e se prolonga em nossas práticas como formadores de professores, há mais de 15 anos. Nossa prática ancora-se em Alarcão (2011), ao elucidar que os formadores de professores têm uma grande responsabilidade na ajuda do desenvolvimento da capacidade de pensar, autônoma e sistematicamente, dos formandos. A autora prossegue dizendo que têm sido de grande valor formativo a pesquisa-ação, "[...] no que concerne à formação de professores" (ALARCÃO, 2011, p. 49).

Inicialmente, definimos os participantes e procuramos prepará-los de forma dialógica para o desenvolvimento das práticas de aproximação das escolas por meio da investigação. Outrossim, os Licenciandos foram escolhidos a partir dos seguintes critérios: (1) interesse em participar; (2) ser Licenciando das disciplinas de Prática de Ensino I de Ciências Biológicas e Prática de Ensino aplicada a Química; e, preferencialmente, estar cursando o Estágio Curricular Supervisionado (ESC). Importante realçar que, na instituição, lócus da pesquisa, o ECS é desenvolvido a partir do quinto período do curso, pelo viés da pesquisa, conforme já afirmamos (PANIAGO et al., 2018). Para tanto, os Licenciandos possuem o apoio das disciplinas supracitadas, todavia, nem todos conseguem inserir-se no ECS quando estão cursando essas disciplinas, em face da dificuldade de conciliar os tempos de estudar e trabalhar. Dessa forma, as ações formativas desta pesquisa envolveram 24 Licenciandos da disciplina Prática de Ensino do curso de Ciências Biológicas e 15 Licenciandos de Prática de Ensino Aplicada à Química, doravante denominados Licenciandos. As atividades foram realizadas em escolas de educação básica, contando, diretamente, com três professores que exerceram o papel de colaboradores e coformadores dos futuros professores.

Para efeitos de apresentação das ações de pesquisa-ação vivenciadas por nós, selecionamos as narrativas de seis Licenciandos, aqui designados, como Paixão, Mimi e Bela, da Licenciatura em Ciências Biológicas; Força, Amor e Tainá, da Licenciatura em Química, identificados com nomes que representam as suas personalidades. Dessa forma, apresentaremos o percurso das atividades realizadas, a partir de nossas narrativas e das narrativas dos participantes. Conforme Alarcão (2011, p. 57), a escrita narrativa é um "[...] encontro conosco e com o mundo que nos cerca. Nele, encetamos uma fala com o nosso íntimo e, se quisermos abrir-nos, também com os outros. Implica reflexões a níveis de profundidade variados. As narrativas revelam o modelo como os seres humanos experienciam o mundo".

Conforme narramos, revisitamos a nossa prática docente e, à luz das teorias, a (re) significamos. Também os Licenciandos, ao narrarem sobre as vivências experimentadas na 
escola de educação básica, por meio de projetos de pesquisa, na relação observada entre professores e alunos, eles analisavam as suas próprias ações como aprendizes pesquisadores. Importa ressaltar que as narrativas têm sido bastante utilizadas em pesquisas na área das ciências humanas e da educação. Connelly e Clandinin (1995, p. 11-12) afirmam a importância do uso, pois "[...] los seres humanos somos organismos contadores de historias, organismos que, individual y socialmente, vivimos vidas relatadas. El estudio de la narrativa, por lo tanto, es el estudio de la forma en que los seres humanos experimentamos al mundo".

Os dados aqui apresentados baseiam-se, portanto, nas narrativas orais e escritas dos pesquisadores e Licenciandos envolvidos. Estas, por sua vez, são também formativas, pois, ao narrarem todos os envolvidos, rememoram as vivências e dão a elas novos significados. Ao narrar a história, as várias vivências, todos nós, autores e participantes, formamo-nos no processo, pois pudemos refletir sobre a trajetória percorrida. Por certo, além de usar as narrativas para elucidar o vivido na pesquisa, elas foram estratégias relevantes utilizadas em nossos momentos formativos, porquanto, motivamos os participantes a falarem de experiências vividas, o que, para Josso (2010, p. 34), "[...] é, pois, uma certa maneira de contar a si mesmo a sua própria história, as suas qualidades pessoais e socioculturais, o valor que se atribui ao que é 'vivido' na continuidade temporal do nosso ser psicossomático". A autorreflexão por meio das narrativas foi um processo rico de aprendizagens, uma vez que contribuiu para o nosso desenvolvimento profissional e aprimoramento de nossas práticas.

Para a apresentação e análise de nossas próprias narrativas e dos Licenciandos, registradas em diários de campo, levamos em conta as diferentes fases de análise de conteúdo propostas por Bardin (2013): (1) a pré-análise; (2) a exploração do material e o tratamento dos dados; (3) a inferência e a interpretação.

De modo geral, a pesquisa foi desenvolvida de acordo com as seguintes etapas: (1) Formação para a pesquisa em sala de aula e em estudos específicos realizados no LIFE; (2) Elaboração dos projetos de ensino perspectivados na pesquisa-ação; (3) Definição dos instrumentos de recolha de dados; (4) Desenvolvimento das atividades de ensino previstas nos projetos dos Licenciandos, nas escolas de educação básica, sob a nossa orientação em parceria com os coformadores; (5) Análise dos dados, sistematização e socialização dos resultados. Assim, delineamos os resultados do que foi vivido, em três categorias de análise. (1) A preparação na e pela pesquisa dos Licenciandos para a aproximação da escola de educação básica; (2) Desenvolvendo olhar investigativo durante o diagnóstico; (3) Práticas de ensino perspectivadas na pesquisa-ação.

\section{A Preparação na e pela Pesquisa dos Licenciandos para a Aproximação da Escola de Educação Básica}

Importa destacar que, em sala de aula, procuramos suscitar nos Licenciandos uma atitude ativa no processo de construção de conhecimentos, considerando "[...] aula como momento e espaço privilegiado de encontro e de ações - não deve ser assistida, mas construída, feita pela ação conjunta de professores e alunos", como sugerem Pimenta e Anastasiou (2014, p. 201, grifo dos autores). Então, durante as aulas, procuramos superar a prática tradicional, subjetivada na exposição oral, aula palestra, lista de exercícios, e avançar para uma ação didática em que os Licenciandos participam, ativamente, do processo de construção de sua aprendizagem; processo que se corporifica por meio de diversas estratégias 
didáticas de ensino e avaliação, tais como seminário, dinâmicas, trabalho com projetos, produção de portfólio, sala de aula invertida, ancoradas nos princípios da metodologia ativa. Conforme Masetto (2018, p. 149), as metodologias ativas "[...] são técnicas, métodos, recursos e estratégias que, pensadas como instrumentos adaptados aos diferentes objetivos de aprendizagem, provocam e incentivam a proatividade e a autonomia dos alunos perante a sua formação".

Então, em nossas aulas, procuramos suscitar os Licenciandos a desenvolverem a autonomia para a própria construção de seu conhecimento, processo que traduz, conforme elucidam Pimenta e Anastasiou (2014, p. 215), "[...] o momento do desenvolvimento operacional, da atividade do aluno por meio da pesquisa, do estudo individual, dos seminários [...]".

Apesar de focar na presente pesquisa as ações pedagógicas realizadas nas disciplinas de Prática de Ensino, ministradas no quinto período de curso das duas Licenciaturas, é importante destacar que esta perspectiva formativa efetiva-se em todas as disciplinas que ministramos, de modo que os Licenciandos já são motivados, durante as aulas, a desenvolverem a autonomia na construção de seu conhecimento e a desenvolverem a habilidade de pesquisa. Entre outras práticas, são provocados a analisarem casos de ensino, com base em situações reais e/ou filmes à luz das teorias estudadas. Para ilustrar, em fundamentos sócio-históricos da educação, os estudantes do segundo período analisam o filme Escritores da liberdade e exercitam a atitude de análise e construção de um artigo. Em Didática, eles analisam os filmes intitulados Como estrela na Terra e $A$ escola da vida, à luz dos conhecimentos teóricos estudados, para identificarem aspectos das práticas de ensino dos professores, situando o campo epistemológico e teórico, no qual ancoram-se. Em outras situações, as práticas acontecem mesmo é na escola, em que, com a autorização dos professores, os Licenciandos observam suas aulas, com vistas a identificar as tendências pedagógicas que subjazem às suas práticas.

Em face do perfil e realidade dos Licenciandos dos cursos de formação inicial de nossa instituição, que estudam no período noturno e trabalham durante o dia, nem todos puderam participar de todo o processo formativo e das práticas de ensino perspectivadas na pesquisa-ação, nas escolas de educação básica, que ocorreram durante o dia. Todavia, de forma indireta, eles participaram, uma vez que tudo o que desenvolvíamos era partilhado em sala de aula, de modo que as práticas de ensino dessas disciplinas se alongavam em atividades extra sala de aula, conectando-se com os projetos de pesquisa e de extensão. Nessa perspectiva, o trabalho com projetos possibilitou o diálogo entre os alunos envolvidos, de forma direta e indireta, bem como o diálogo entre os formadores, IES e escola. Em cômputo geral, desenvolvemos um processo conforme segue:

1. Estudo, em sala de aula e para além dela, de questões que envolvem a pesquisa em educação/ensino e seu papel na formação do professor, planejamento, metodologias ativas, estratégias didático-pedagógicas diversas. As discussões eram momentos em que os Licenciandos externavam as dúvidas, inquietações acerca do vivido na escola, num processo de reflexão na ação, sinalizando a construção da autonomia na ação de se constituírem como professores pesquisadores;

2. Preparação para a recolha dos dados: orientamos os Licenciandos para o processo de recolha de dados, por meio de observação com registro em diário de campo, entrevistas com os professores da escola de educação básica e o uso do questionário 
com os alunos. Para tanto, eles construíram roteiros para o processo de recolha das entrevistas narrativas;

3. Tabulação e análise dos dados, fundamentada nos referenciais teóricos indicados: orientamos os alunos a destacarem elementos, categorias de análise, a partir das situações vivenciadas na escola e sala de aula;

4. Sistematização dos dados: considerando que uma das etapas da pesquisa é a publicação dos resultados, os Licenciandos foram desafiados ao processo de escrita do vivido durante a imersão na escola. Para tanto, o grande desafio foi a análise reflexiva das vivências, a tabulação categorial dos dados coletados em diálogo com a teoria estudada.

\section{Desenvolvendo o Olhar Investigativo durante o Diagnóstico}

Concomitante ao processo de estudos, inicialmente, orientamos os Licenciandos a recolherem as entrevistas narrativas dos professores coformadores e a observarem a realidade da escola, conforme o que fora descrito anteriormente, com vistas a identificar as principais dificuldades em sala de aula e aspectos socioculturais da comunidade educativa que interferiam, diretamente, na qualidade do processo ensino e aprendizagem dos alunos. Nesse sentido, destacamos a importância de primeiro conhecer a escola, depois pensar em contribuir, de forma cooperativa, com alguma ação didática. Pimenta e Lima (2017, p. 187) nos ajudam ao afirmar que, "[...] no diagnóstico de uma escola, precisamos observar atentamente os sintomas disciplina, violência, desinteresse para podermos encontrar as causas dos problemas vividos pela escola, pelos alunos e pelos professores".

Dessa forma, inicialmente sob a nossa orientação, os licenciandos, com um olhar investigativo, atento sobre as questões complexas vivenciadas na comunidade educativa, observaram as diversas relações e práticas de ensino dos professores das escolas participantes do projeto. Neste sentido, eles pronunciam:

\begin{tabular}{|l|l|}
\hline Força & $\begin{array}{l}\text { Oprimeiro contato com o ambiente escolar foi relevante para o conhecimento estrutural, administrativo, e pedagógico } \\
\text { de cada colégio. Foi diferente ver a escola como estudante de graduação, vi coisas que não via antes. }\end{array}$ \\
\hline Mimi & $\begin{array}{l}\text { Me impressionei com a realidade da escola, era uma escola de tempo integral, mas sem condições de espaço. As salas } \\
\text { eram muito apertadas, os alunos saiam da sala apenas para almoçar e lanchar. Eu tinha pensado em várias atividades, } \\
\text { inclusive em aplicar experimentos, jogos; mas como fazer isto, se a escola quase não tinha espaço nem para as aulas? }\end{array}$ \\
\hline
\end{tabular}

Como se observa, as narrativas de Mimi e Força sinalizam a importância de se conhecer a escola, antes de planejar alguma prática de ensino. Força explica que agora, como estudante de Licenciatura, olha a escola de forma diferente do que quando aluno da educação básica. Mimi, inclusive, pensou em aplicar experimentos, mas percebeu que era preciso pensar em como materializar essas estratégias didáticas, em face do pouco espaço que a escola possui. Em contrapartida, outra licencianda afirma:

\begin{tabular}{l|l} 
Tainá & $\begin{array}{l}\text { Ao analisar a realidade da escola, percebi que escola tem um ótimo espaço para a realização de aulas extras salas, tipo } \\
\text { laboratório e uma área em que cultivam plantas medicinais e hortaliças. Também vi que os professores desenvolvem } \\
\text { vários projetos, como: meio ambiente, sarau literário, feira de ciências, função social, entre outros. }\end{array}$
\end{tabular}

A narrativa de Tainá evidencia uma situação diversa da sinalizada por Mimi, em termos dos espaços físicos e pedagógicos da escola, inclusive, Tainá acrescenta que " $a$ escola dispõe de laboratório de ciências, nele, contém vidrarias, instrumentos para realização 
de experimentos, reagentes, livros, esqueletos, microscópio, globo, pias, projetor, quadro negro, bancadas, espécies em conservações. Pensei, então, em como poderia ser a minha intervenção". $\mathrm{Na}$ mesma direção, outro licenciando reconhece a importância de se realizar o diagnóstico:

\begin{tabular}{|c|l|}
\hline Amor & $\begin{array}{l}\text { Odiagnóstico foi importante para conhecer a escola antes da realização de alguma prática, já que, além da perspectiva } \\
\text { física e estrutural do colégio, buscou-se observar questões relacionadas ao ensino e aprendizagem como, metodologias } \\
\text { já adotadas pela professora e conteúdos programáticos para, posteriormente, escolher as estratégias didáticas } \\
\text { adequadas à realidade dos alunos e ao seu ritmo de aprendizagem. }\end{array}$ \\
\hline
\end{tabular}

As narrativas dos Licenciandos sinalizam atitude questionadora e investigativa durante a realização do diagnóstico na escola, ao se analisar os diversos aspectos que influenciam no processo ensino e a prendizagem dos alunos. Além disso, eles se aproximaram dos professores coformadores, avançando da perspectiva tão criticada por Zeichner (2010, p. 484): "[...] é muito comum, por exemplo, que os professores regentes, com os quais os estudantes trabalham durante sua passagem pela escola, saibam muito pouco sobre a especificidade das disciplinas de metodologia e fundamentos que seus estagiários completaram na universidade".

Dessa forma, além de aproximar os Licenciandos das práticas de educação básica, preocupamos-nos com o processo formativo consubstanciado no diálogo com os coformadores e na pesquisa-ação. Com isso, eles estavam desenvolvendo as habilidades de pesquisa, construindo a sua identidade de pesquisador, durante o processo de observação do cotidiano escolar e posterior ação didática. Tal como ocorre no estágio, ao transitar da instituição formadora para a escola e vice-versa,

Os estagiários podem tecer uma rede relações, conhecimentos e aprendizagens, não com o objetivo de copiar, criticar apenas os modelos, mas no sentido de compreender a realidade para ultrapassá-la. Aprender com os professores de profissão como é o ensino, como é ensinar, é o desafio a ser aprendido/ensinado no decorrer dos cursos de formação no estágio. (PIMENTA; LIMA, 2017, p. 105).

E nesse vai e vem da instituição formadora e vice-versa, no contato com os alunos, com os professores, que os Licenciandos vão construindo diversas aprendizagens que contribuem para a construção de seus saberes e identidade docente, tal como afirmam Pimenta e Lima (2017, p. 105): "A identidade constrói-se com base no confronto entre as teorias e as práticas, na análise sistemática das práticas à luz das teorias, na elaboração de teorias [...]".

Além da observação da realidade escolar, os Licenciandos recolheram narrativas por meio de entrevistas com os professores da educação básica e registraram em diário de campo, objetivando entender melhor o trabalho docente e identificar os conteúdos de Ciências que os alunos apresentam maior dificuldade de compreensão. Com base nessas entrevistas narrativas, os estudantes identificaram várias necessidades educativas apontadas pelos professores, que perpassam desde problemas socioculturais, econômicos dos alunos à precariedade das condições de trabalho dos professores, em termos de falta de tempo para planejamento e da falta de recursos em sala de aula. Do ponto de vista do processo ensino e aprendizagem de Ciências, de acordo com as análises dos Licenciandos das entrevistas narrativas, os professores sinalizaram alguns conteúdos que exigem um grau maior de abstração e que os alunos dos anos finais possuem dificuldades, tais como o sistema solar. Nesta direção, os professores solicitaram aos Licenciandos que desenvolvessem, em suas práticas de ensino, diferentes estratégias didáticas para o ensino e aprendizagem, 
considerando a dificuldade que possuem para o planejamento e elaboração de recursos e estratégias, enfim de métodos de ensino alternativos, em face da longa jornada de trabalho.

Não obstante, os Licenciandos coletaram dados junto aos alunos dos anos finais do Ensino Fundamental, na disciplina de Ciências, das escolas envolvidas. Para tanto, aplicaram um questionário sociocultural, com vistas a identificar o perfil dos alunos, as suas dificuldades de ensino e aprendizagem. No levantamento das informações sobre os alunos, os Licenciandos perceberam que as escolas estavam inseridas em um contexto sociocultural marcado por vários problemas advindos de questões econômicas, pais separados, enfim, os alunos sinalizaram carências afetivas e necessidades econômicas. "Ao analisar os dados recolhidos com os alunos, ficou evidente que eles possuem muitas dificuldades, com pais ganhando salários baixos, outros nem moram com os pais e sim com avós [...]" (Força).

Por certo, a inserção dos Licenciandos no cotidiano escolar, imbuídos da teoria, possibilitou várias reflexões, no sentido de perceberem que o processo ensino e aprendizagem dos alunos são, diretamente, influenciados pelos diversos intervenientes que os rodeiam. Assim, a materialização de qualquer ação didática implica em questionar: quem são esses alunos e onde estão inseridos? Como aprendem? Quais os elementos socioculturais, econômicos, políticos desta realidade? Conforme já verificamos (PANIAGO, 2017). A narrativa de Força segue nesta direção: "Aplicar o questionário foi importante para fundamentar e nos nortear nas intervenções pedagógicas propostas, pois, através deste instrumento, foi possível conhecer aspectos do meio em que os alunos estão inseridos e qual a sua realidade." Na mesma direção, afirma outro licenciando, "percebeu-se o interesse dos alunos em atividades dinâmicas. Baseando nos pressupostos da metodologia de ensino ativa, que coloca o aluno como protagonista em sua aprendizagem, desenvolvemos algumas atividades com jogos didáticos." (Paixão).

$\mathrm{Na}$ análise dos dados junto aos alunos, os Licenciandos perceberam a necessidade de os professores trabalharem de forma diferente, com o uso de outras estratégias e recursos didáticos que superem a utilização, quase que exclusiva, do livro didático, tão conhecido por eles. "Os alunos, de forma geral, solicitaram que gostavam quando tinha aula prática, fora de sala, e se fosse em sala, que fosse diferente do ensino do livro." (Paixão). Também Tainá explica "[...] foram observadas as condições sociais, a aprendizagem dos conteúdos de Ciências e os alunos indicaram que queriam estudar os conteúdos de forma diferente, com mais práticas e atividade mais dinâmicas." Conforme se observa, os Licenciandos definiram o tema do projeto a partir da observação na escola, do diálogo com os coformadores e uso do questionário com os alunos. O olhar investigativo, à luz da teoria, possibilitou que problematizassem a realidade escolar e definissem ações possíveis de serem colocadas em prática.

Os dados observados na pesquisa diagnóstico sinalizaram a necessidade de trabalho com diferentes metodologias, estratégias e recursos didáticos que chamem a atenção dos alunos. Então, decidimos não focar, apenas, em conteúdos específicos, mas em explorar temas transversais, de modo a favorecer a autonomia dos estudantes no processo de construção de seu conhecimento. Conforme é apresentado nos Parâmetros Curriculares Nacionais (PCN) (BRASIL, 1998, p. 23), "[...] é necessário favorecer o desenvolvimento de postura reflexiva e investigativa, de não-aceitação, a priori, de ideias e informações, assim como a percepção dos limites das explicações, inclusive dos modelos científicos, colaborando para a construção da autonomia de pensamento e de ação".

Além do mais, é importante realçar que o foco da nossa pesquisa são as aprendizagens dos futuros professores, então, não seria possível resolver todas as mazelas envolvendo 
o processo ensino e aprendizagem de Ciências na educação básica. Em alguns casos, os coformadores indicaram os temas, conforme sinaliza Tainá: "Feito o levantamento inicial, em diálogo com o professor da turma, foram selecionados alguns temas que seriam trabalhados no 3 e $4^{\circ}$ bimestre de 2017. Os conteúdos destacados foram Nutrição: composição dos alimentos e importância dos nutrientes no organismo, e pirâmide alimentar." Também outro Licenciando vai nessa direção: "Pensamos, em 2017, segundo semestre, em trabalhar a alimentação saudável, nutrição e para 2018 o sistema solar. Então, depois de definido, teríamos que pensar em como ensinar de forma diferente, eis o desafio." (Força).

Diferentemente, um grupo de Licenciandos de outra escola caminhou em outra direção, conforme afirma Bela, ao perceber que a escola possuía um laboratório, todavia, encontrava-se desativado, juntamente à coformadora, pensou em reorganizá-lo para as aulas de Ciências:

\begin{tabular}{|l|l|}
\hline Bela & $\begin{array}{l}\text { Percebemos que a escola tinha um laboratório que estava desativado. Partindo disso, por que não fornecer para } \\
\text { a escola a reorganização de um laboratório completo e que atualmente não está sendo utilizado? É uma forma } \\
\text { de intervenção sem custos para a unidade escolar e que proporciona um ambiente agradável para a realização } \\
\text { de atividades práticas e experimentais por parte dos professores de Ciências. Eestas atividades são uma excelente } \\
\text { estratégia didática utilizada no processo de ensino e aprendizagem. }\end{array}$ \\
\hline
\end{tabular}

Ao incitar o desenvolvimento de projetos em grupo, caminhamos no sentido de possibilitar a aprendizagem dos Licenciandos para o desenvolvimento de ações cooperativas que os capacitassem para as habilidades de pesquisa, e de buscarem contribuir para a prática de ensino de Ciências dos professores coformadores.

Dessa forma, elaboramos um projeto de pesquisa guarda-chuva, cujo foco foi a produção, desenvolvimento e avaliação de materiais didáticos perspectivados nas metodologias ativas, este, que, por sua vez, desmembrou-se em vertentes que englobavam os projetos de ensino e de extensão desenvolvidos sob a nossa coordenação. Após a seleção dos temas, os Licenciandos elaboraram os projetos em dupla e/ou trinca, sob a supervisão dos professores formadores e coformadores. Os projetos de ensino perspectivados na pesquisaação focalizaram, em sua totalidade, as questões dos processos de ensino e aprendizagem no campo do ensino de Ciências. Portanto, nos procedimentos metodológicos, os Licenciandos descreveram a sequência didática a ser trabalhada em sala de aula.

Todo o processo ocorreu de forma cíclica, tal como propõe Alarcão (2011, p. 54), ação, reflexão sobre a ação e (re)significação da ação, considerando que,

[...] compreendido o problema, urge planificar a solução de ataque e pôla em execução para, em seguida, se observar o que resulta da experiência, se conceptualizarem resultados e problemas emergentes, se planificar ou replanificar, entrando, assim, num novo ciclo de aspiral da pesquisa-ação.

Assim, de modo geral, o processo de aproximação da escola de educação básica e posterior ação didática no ensino de Ciências, nos anos finais do ensino fundamental, em grupos, desenrolaram-se nos anos de 2017, 2018 e 2019, de acordo com as seguintes etapas: ambientação para conhecer a realidade escolar e prática de ensino dos coformadores, identificação dos conteúdos de difícil compreensão para os alunos da disciplina de Ciências nos anos finais do Ensino Fundamental; construção, desenvolvimento da prática e avaliação de materiais didático-pedagógicos para o ensino de Ciências; reflexão dialógica sobre as ações desenvolvidas com vistas a (re)significá-las. 
Como os projetos eram desenvolvidos de forma cooperativa, na sua materialização, enquanto um trabalhava, os demais assistiam e faziam as anotações, registravam todo o processo, para, depois, esse ser objeto de reflexão e sistematização em portfólio e/ou relatório. Para tanto, usavam o diário de campo e fotografias. Em todo o processo, incitávamos um processo de reflexão na ação, considerando que, conforme Alarcão (2011, p. 54), "[...] a reflexão na ação acompanha ação em curso e pressupõe uma conversa com ela".

\section{As Práticas de Ensino dos Licenciandos na Perspectiva da Pesquisa-Ação}

O projeto de pesquisa guarda-chuva, cujo foco foram as práticas de ensino de Ciências na educação básica, com o uso de diversas alternativas didático-pedagógicas, traduziuse em ações coletivas, em que a equipe reunia-se para estudos, reflexão, avaliação, enfim discutir elementos teóricos e práticos que possibilitariam a (res) significação das práticas de ensino desenvolvidas na escola. Intitulado Alternativas de melhorias no processo ensino e aprendizagem de Ciências nos anos finais do Ensino fundamental, o projeto guarda-chuva objetivou identificar métodos de ensino alternativos baseados em metodologias ativas, construir e discutir modos de aplicação dos materiais didático-pedagógicos, vinculando os subprojetos dos Licenciandos das disciplinas de Prática de Ensino Aplicada à Química, Prática de Ensino de Ciências e outros projetos que desenvolvemos no LIFE. Destacaremos abaixo alguns dos projetos com respectivos objetivos.

Em 2017, foram desenvolvidos os projetos: (1) O uso das tecnologias digitais de informação e comunicação em sala de aula, com o objetivo de trabalhar o uso das Tecnologias Digitais de Informação e Comunicação (TDIC) nas aulas de Ciências; (2) O uso de diferentes estratégias didático-pedagógicas para o trabalho com o processo ensino e aprendizagem de ciências, o qual objetivou investigar diferentes estratégias didático-pedagógicas para o trabalho com o processo ensino e aprendizagem de Ciências no $6^{\circ}$ ano; (3) Buscando novas metodologias para o ensino de ciências, teve como finalidade buscar novas alternativas didático-pedagógicas, com vistas a dinamizar e melhorar o ensino e aprendizagem de Ciências.

Em 2018, desenvolvemos: (1) Revitalização do laboratório de Ciências, que objetivou revitalizar o laboratório de Ciências que se encontrava desativado; (2) Atividades investigativas, estimulando a autonomia do aluno nas aulas de Ciências e Química, para desenvolver nos alunos um espírito investigativo de aprendizagem, a fim de se tornarem mais participativos e críticos durante as aulas de ciências; (3) Uma problematização do tema alimentação saudável com estudantes do ensino fundamental, que objetivou verificar o conhecimento dos alunos do ensino fundamental, no que diz respeito à alimentação saudável e o cerrado brasileiro.

E, por fim, em 2019, tivemos: (1) Trilha ecológica interativa na perspectiva da educação ambiental, com o propósito de oportunizar vivências pedagógicas em uma trilha ecológica interativa; (2) Práticas colaborativas em Ciências naturais por meio de metodologias ativas, teve como objetivo produzir e desenvolver práticas pedagógicas, ancoradas na metodologia de ensino ativa; (3) Cultivo de plantas visando o aproveitamento de materiais recicláveis, cuja intenção foi promover a reflexão sobre alimentação e saúde, a partir de hábitos alimentares e ações ecológicas. 
O nosso trabalho caminhou no sentido das experiências com estágio defendidas por Pimenta e Lima (2017, p. 189), para as quais, "[...] a realização de estágio em forma de projetos desenvolve uma atitude de autonomia e de criatividade dos estagiários, uma vez que possibilita a descoberta de espaços de intervenção significativa para a sua formação e para as escolas". Para tanto, os Licenciandos elaboraram os projetos de ensino perspectivados na pesquisa-ação, ancorados em referenciais teórico-metodológicos, conforme o citado, e desenvolveram as práticas com os alunos da educação básica. De modo geral, as práticas desenvolvidas nos projetos ocorreram nas escolas de educação básica e no IF Goiano - câmpus Rio Verde, de modo que destacaremos alguns dos excertos dos Licenciandos a respeito desse processo formativo.

Nas práticas desenvolvidas nas escolas, ao relatarem as diferentes estratégias didáticopedagógicas utilizadas para trabalhar os conteúdos de Ciências, eles relatam:

\begin{tabular}{|l|l|}
\hline Força & $\begin{array}{l}\text { Trabalhamos várias estratégias no ensino dos conteúdos. Por exemplo, para trabalharmos alimentação e nutrição, } \\
\text { organizamos vários recursos didáticos, tais como: jogos, cardápios, maquetes da pirâmide. Tivemos o cuidado } \\
\text { para envolver os alunos no processo de construção dos materiais didáticos. Construímos o esboço de } 15 \text { pirâmides } \\
\text { alimentares em papel sulfite. }\end{array}$ \\
\hline Tainá & $\begin{array}{l}\text { Objetivando dinamizar o trabalho do processo-ensino aprendizagem do conteúdo 'Alimentação saudável'. Para efetuar } \\
\text { esta ação, procuramos incitar os alunos a produzirem e participarem de forma ativa no processo ensino e aprendizagem. }\end{array}$ \\
\hline Bela & $\begin{array}{l}\text { Ao estudar e me aprofundar nos aspectos das Metodologias Ativas e suas diversas possibilidades, foi relativamente } \\
\text { simples elaborar uma prática para aplicarmos em uma escola, conforme as orientações da atividade proposta. }\end{array}$ \\
\hline
\end{tabular}

Conforme se observa, as práticas dos Licenciandos contribuíram para o desenvolvimento de sua identidade docente como pesquisadores, bem como suscitaram, nos alunos da educação básica, o desenvolvimento da autonomia, da responsabilidade pela construção de seu conhecimento. Ademais, as práticas de ensino perspectivadas na pesquisaação, desenvolvidas pelos Licenciandos, caminharam no sentido de apoiar os professores coformadores com o uso de estratégias metodológicas diversas em sala de aula.

\begin{tabular}{|l|l|}
\hline Paixão & $\begin{array}{l}\text { Realizou-se um projeto em que o objetivo foi trabalhar metodologias de ensino ativa. Para tanto, desenvolvemos } \\
\text { intervençóes práticas em uma escola com os alunos de Ciências do oitavo ano do Ensino Fundamental. }\end{array}$ \\
\hline Mimi & $\begin{array}{l}\text { Em outra prática, utilizamos como instrumento didático o jogo do tabuleiro. O jogo foi confeccionado e adaptado } \\
\text { para essa atividade. É composto pelo tabuleiro, perguntas relacionadas ao tema, pinos e um dado. Todo material foi } \\
\text { produzido no LIFE. Os alunos foram divididos em duas grandes equipes. Além de promover a socialização dos alunos, } \\
\text { o jogo proporcionou uma revisão de conteúdos estudados por meio das perguntas. }\end{array}$ \\
\hline Bela & $\begin{array}{l}\text { Em nosso projeto além de revitalizar o laboratório que estava desativado, pudemos desenvolver várias práticas } \\
\text { experimentais com o ensino de Ciências e percebemos que os professores começaram a fazer uso dele também. }\end{array}$ \\
\hline
\end{tabular}

Além das diversas estratégias didáticas utilizadas nos projetos, tais como experimentos, jogos manuais produzidos pelos Licenciandos no LIFE, também foram produzidos jogos eletrônicos no projeto $O$ uso das tecnologias digitais de informação e comunicação em sala de aula, desenvolvido em parceria com alunos dos cursos de Licenciaturas em Química, Biologia e Engenharia Ambiental. Para o desenvolvimento do jogo, foi utilizada a EngineConstruct2 (HTML5 Game Engine) e RpgMaker MV, em termos de programação e desenvolvimento. Um dos Licenciandos narra sobre o processo de construção do jogo que trata do tema lixo.

\begin{tabular}{|l|l|}
\hline Força & $\begin{array}{l}\text { Ojogo teve a finalidade de sensibilizar os alunos sobre o descarte do lixo de maneira correta. Após ter construído o } \\
\text { jogo da separação do lixo, ao fazer inicialmente o teste com crianças entre } 9 \text { a } 14 \text { anos, foram identificadas algumas } \\
\text { necessidades de mudanças, por exemplo, as crianças sinalizaram que era preciso: aumentar a dificuldade do jogo, } \\
\text { finalizando o jogo caso a criança descartasse o lixo seis vezes em local indevido, adicionar mais figuras de produtos } \\
\text { orgânicos. }\end{array}$
\end{tabular} 
Além das práticas desenvolvidas nas escolas, foram oportunizadas atividades no IF Goiano, no contexto dos projetos e outros eventos em que os alunos da educação básica, além de participarem de atividades diversas, puderam apresentar os resultados das atividades, tais como: I Feira de Ciências e o Circuito Beija Flor ${ }^{3}$, conforme anuncia um Licenciando "[...] tivemos a oportunidade de orientar os alunos da educação básica, dos anos finais do ensino fundamental a elaborar uma pesquisa simples sobre os nutrientes presentes nos alimentos $e$ apresentar na Mostra de Ciências" (Paixão). Então, segundo os Licenciandos, os alunos do ensino fundamental foram desafiados a pesquisarem acerca da alimentação saudável e apresentaram os resultados em mostras organizadas no IF Goiano.

\begin{tabular}{|l|l|}
\hline Força & $\begin{array}{l}\text { A prática consistiu no recolhimento e análise de dados pelos alunos do } 7^{\circ} \text { ano do cardápio da escola. Esta recolha de } \\
\text { dados foi referente aos principais ingredientes que constitui os lanches de cada dia da semana. E averiguar segundo } \\
\text { as condições financeiras da escola se o lanche oferecido é satisfatório. }\end{array}$ \\
\hline Paixão & $\begin{array}{l}\text { Os alunos foram incentivados a pesquisar e apresentar os projetos de iniciação à pesquisa, realizados por alunos } \\
\text { da turma envolvida na experiência em um evento intitulado Feira de Ciências, organizado pelo IF Goiano, Câmpus } \\
\text { Rio Verde. }\end{array}$ \\
\hline
\end{tabular}

De fato, ensinar na e pela pesquisa é um processo complexo para um professor já experiente, o desafio se alarga, por se tratar de Licenciandos inexperientes. Mesmo assim, eles procuraram trabalhar com os alunos da educação básica, por meio de um processo de ensino perspectivado na investigação. Tão o é, que o Licenciando narra, após a recolha e análise dos dados, que os alunos da educação básica foram orientados para a escrita e apresentação dos resultados: "Após a recolha e análise dos dados, os alunos foram orientados sobre a forma como o trabalho seria apresentado. Ao escrever e construir o banner, observou-se quanto à forma escrita, frases que os auxiliassem na apresentação pois, a falta de experiência em apresentações para um público maior pode pesar." (Força).

Além da participação em Mostras de Ciências, os Licenciandos envolveram, durante os projetos, os alunos da educação básica em outras práticas no IF Goiano, tais como a trilha e os experimentos nos laboratórios. As narrativas sinalizam este processo:

\begin{tabular}{|l|l|}
\hline Amor & $\begin{array}{l}\text { No nosso projeto da trilha, fizemos exposição de cartazes contendo curiosidades sobre fauna e flora, dados sobre a } \\
\text { situação do meio ambiente, orientações sobre preservação e abordagens sobre o bioma Cerrado. Durante a caminhada } \\
\text { na Trilha, fizemos paradas estratégicas nos cartazes, a fim de explicarmos sobre cada tema e socializar opiniões e } \\
\text { discutir estratégias de preservação. Ao final do percurso, fizemos um círculo no gramado, onde os alunos fizeram } \\
\text { perguntas e comentários sobre a vivência da Trilha. }\end{array}$ \\
\hline Paixão & $\begin{array}{l}\text { Além das práticas na escola, trabalhamos também no IF. Nessa prática, meu grupo trabalhou com a produção de } \\
\text { lâminas histológicas que foram observadas no microscópio. }\end{array}$ \\
\hline Mimi & $\begin{array}{l}\text { Pudemos proporcionar aulas diferentes, ao ar livre embaixo das palmeiras, unindo teoria e prática; os alunos puderam } \\
\text { manusear, ver não só em livros e até levar para casa. }\end{array}$ \\
\hline
\end{tabular}

Em cômputo geral, constatamos que a pesquisa pode ser uma estratégia fundamental para a articulação entre a formação inicial e o campo de trabalho dos Licenciandos, conforme destacam:"adisciplinapromoveu um contato próximo comoque seránossarealidade profissional, e me ressaltou a importância do planejamento de aula, do trabalho com projetos de ensino e pesquisa com a utilização de estratégias didáticas diversas, como metodologias ativas" (Amor). Seguida de Bela: "[...] o trabalho com projetos na disciplina possibilitou, por meio de um olhar

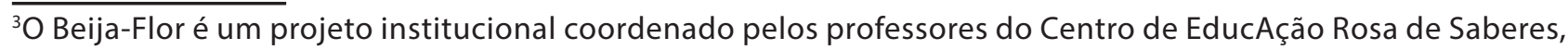
juntamente à diretoria de pesquisa e extensão, cujo objetivo é aproximar o IF Goiano da comunidade local, visando a promoção da Ciência pelo viés da Educação Ambiental. 
sensível, fundamentado teoricamente, que enxergássemos como futuras profissionais capazes de executar suas funções, e vai além disso, podemos e devemos ser mediadores do conhecimento e também os produtores de conhecimentos relacionados aos problemas educacionais".

\section{Considerações Finais}

Os resultados dessa pesquisa, que se encontra em andamento, sinalizam a importância da formação inicial na e pela pesquisa, como estratégia de a proximação do cotidiano da escola de educação básica, ou seja, para a articulação da teoria e a prática num processo reflexivo e investigativo. As práticas de ensino perspectivadas na pesquisa-ação possibilitaram, aos Licenciandos, o estudo, a análise, a problematização e a busca de soluções às diversas situações didáticas do ensino e aprendizagem de ciências.

As atividades vivenciadas na pesquisa oportunizaram um trânsito de mão dupla, do IF Goiano para a escola e da escola para a IF Goiano, tendo em vista que os professores e alunos da educação básica estiveram em vários momentos na IES, seja para participarem de um processo formativo, ou de aulas práticas desenvolvidas pelos Licenciandos no LIFE e em outros laboratórios, tais como o de Zoologia e Química, Informática; bem como os Licenciandos, mesmo os que estavam no início do curso, foram inseridos no cotidiano escolar para aprendizagens diversas.

As narrativas, aqui apresentadas, traduzem as práticas dos pesquisadores, articuladas entre as disciplinas dos cursos de Licenciatura e as práticas de ensino dos Licenciandos de aproximação do cotidiano da educação básica perspectivadas na pesquisa-ação. Neste cenário, o LIFE constituiu-se em espaço de reflexão-ação-reflexão e de produção de materiais didático-pedagógicos, com vistas à articulação das práticas formativas dos docentes que atuam nas Licenciaturas e outros cursos. Ademais, as práticas vivenciadas na pesquisa estão aproximando os formadores e consolidando a pesquisa em ensino no contexto de uma IES com apenas uma década de experiência com a formação de professores.

Destacamos, ainda, como resultados, a materialização do tripé: pesquisa, ensino e extensão; uma relação necessária na instituição, pois, à medida que abordamos práticas em sala de aula nas disciplinas, realizamos pesquisa para análise do material didático produzido e estendemos as ações às escolas de educação básica, de modo a aproximar os futuros professores de ciências de seu contexto de atuação profissional na e pela pesquisa.

Realçando que nossa prática de ensino assentou-se num trabalho perspectivado na pesquisa pedagógica, uma vez que, além de incitarmos os Licenciandos a pesquisarem aspectos ligados às questões do ensino e seus intervenientes, também problematizamos nossa prática de ensino enquanto professores formadores, pesquisando e oportunizando novas formas de ensino e aprendizagem no processo formativo, enfim, colocando a investigação a serviço da educação e do nosso próprio desenvolvimento profissional. Conforme Vieira (2017, p. 141), "[...] também os formadores devem investigar pedagogicamente, buscando possibilidades de construção de uma formação transformadora e emancipatória no seu contexto de trabalho".

Logo, ressaltamos, a partir da análise dos dados já obtidos na pesquisa ainda em desenvolvimento, a possibilidade de se investigar as práticas de ensino desenvolvidas no espaço escolar, a fim de intervir para melhoria da aprendizagem escolar, bem como promover práticas nos cursos de formação inicial de professores que possibilitem a formação reflexiva dos futuros professores de ciências, com vistas a contribuir para re(significação) de ações de ensino vivenciadas na escola. 


\section{Referências}

ALARCÃO, I. Professores reflexivos em uma escola reflexiva. 8. ed. São Paulo: Cortez, 2011.

BARDIN, L. Análise de conteúdo. 5. ed. Lisboa: Edições 70, 2013.

BRASIL. Ministério da Educação. Parâmetros curriculares nacionais. Brasília: MEC: SEF, 1998.

CONNELLY, M.; CLANDININ, J. Relatos de experiencia e investigación educativa. In: LARROSA BONDÍA, J. et al. (comp.). Déjame que te cuente: ensayos sobre narrativa y educación. Barcelona: Laertes, 1995. p. 11-59.

FLORES, M. A. Algumas reflexões em torno da formação inicial de professores. Educação, Porto Alegre, v. 33, n. 3, p. 182-188, 2010.

GHEDIN, E.; FRANCO, M. A. S. Questões de método na construção da pesquisa em educação. São Paulo: Cortez, 2008.

JOSSO, M. Experiência de vida e formação. São Paulo: Paulus, 2010.

MASETTO, M. T. Trilhas abertas na universidade: inovação curricular, práticas pedagógicas e formação de professores. São Paulo: Sumus, 2018.

MIZUKAMI, M. G. N. Escola e desenvolvimento profissional da docência. In: GATTI, B. A. et al. (org.). Por uma política nacional de formação de professores. São Paulo: Ed. Unesp, 2013. p. 23-54.

PANIAGO, R. N. Contribuições do programa institucional de bolsa de iniciação para a aprendizagem da docência profissional. 2016. 367 f. Tese (Doutorado em Ciências da Educação) - Universidade do Minho, Braga, 2016.

PANIAGO, R. N. Os professores, seu saber e seu fazer: elementos para uma reflexão sobre a prática docente. Curitiba: Appris, 2017.

PANIAGO, R. N.; SARMENTO, T. Formação na e para a pesquisa no PIBID: possibilidades e fragilidades. Educação \& Realidade, Porto Alegre, v. 42, n. 2, p. 771-792, abr./jun. 2017.

PANIAGO, R. N.; SARMENTO, T. J.; MEDEIROS, J; NUNES, P. G. Um cenário de possibilidades para o estágio curricular supervisionado no contexto de um instituto federal. Ensaio, Belo Horizonte, v. 20, e11044, 2018.

PIMENTA, S. G; ANASTASIOU, L. G. C. Docência no ensino superior. 5. ed. São Paulo: Cortez, $2014 .$.

PIMENTA, S. G.; LIMA, M. S. L. Estágio e docência. 8. ed. São Paulo: Cortez, 2017.

TARDIF, M. Saberes docentes e formação profissional. 15. ed. Petrópolis: Vozes, 2013.

VIEIRA, F. Entre a reprodução e transformação: a investigação como prática pedagógica na formação de professores. In: FLORES, M. A.; MOREIRA, M. A.; OLIVEIRA, L. R. Desafios curriculares e pedagógicos na formação de professores. 2. ed. Santo Tirso: De Facto Editores, 2017. p. 107-118.

ZEICHNER, K. M. A formação reflexiva de professores: ideias e práticas. Lisboa: Educa, 1993.

ZEICHNER, K. M. A pesquisa-ação e a formação docente voltada para a justiça social: um estudo de caso dos Estados Unidos. In: DINIZ-PEREIRA, J. E; ZEICHNER, K. M. A pesquisa na formação e no trabalho docente. 2. ed. Belo Horizonte: Autêntica, 2008. p. 67-94.

ZEICHNER, K. M. Repensando as conexões entre a formação na universidade e as experiências de campo na formação de professores em faculdades e universidades. Educação, Santa Maria, v. 35, n. 3, p. 479-504, 2010. 